\title{
E-Health Literacy and Availability of Internet Wellness Information on Fast Food among Adolescents in Awka South, Anambra State
}

\author{
Gloria Chukwuemeka, $\mathrm{PhD}$ \\ Department of Mass Communication \\ Nnamdi Azikiwe University, Awka, Anambra State \\ gloria.chukwuemeka69@gmail.com
}

\begin{abstract}
This study focused on e-health literacy and availability of Internet wellness information on fast food among adolescents. The avalanche of data on the Internet indicates that adolescents are likely to be influenced by online information on fast food. This study examined how exposure to online information induces dietary behaviour change among adolescents of Awka South, Anambra State. The study examined two theories: Health Belief Model that explains health behaviour and possible reasons for non-compliance with recommended health actions, and uses-and-gratifications approach which examines why and how people actively seek out particular media to satisfy specific needs. The study adopted a survey of 400 respondents using Cochran sample determination technique. The questionnaire was the instrument for data collection. Findings of the study showed that online wellness information induces dietary behaviour change and increased exposure to negative information about a product reduces the chances of its continued consumption.
\end{abstract}

Keywords: E-health, Fast Food, Literacy, Wellness Information

\section{INTRODUCTION}

E-Health literacy is a term that describes the concept of an individual's ability to access health information from electronic sources to address specific health challenges (Norman and Skinner, 2006). E-Health literacy has become an essential topic of research in recent years. Stellefson, Hanik, Chaney, Chaney, Tennant and Chavarria(2011) state that with a search engine, checking of emails and other online activities are actualised. In recent years, individuals have gained access to a multitude of health information via the Internet.Currently, Nigeria has significant number of people that have access to the Internet among the developing nations.

The emergence of the Internet has changed the use of information and the way we carry out tasks. Richards, Colman, and Hollingsworth (1998) observe that Internet-based health information appeals to consumers with different learning styles. It merges the expansive reach of mass communication channels with the persuasive features of interpersonal channels by giving room for feedbacks between the sender, message and receiver (Cassell, Jackson and Cheuvront, 1998).

Consumers want information about prevention, both for self-care and to participate in a more informed way in their healthcare (Yuri Quintana, Feightner, Wathen, Sangster and Marshall, 2001). An average youth appears more technology savvy than their adult counterparts. Fe 
today's young people, computers, and all their associated applications existed in today's world; machines are as much an accepted part of their environment. The Internet increasingly is used to promote health behaviour.

The Internet is an essential source of health information for adolescents who are yet to establish a relationship with a doctor other than their family doctor. Increased access to health information could create a more informed and healthful youth. Adolescents constitute viable online group that explore vast online information on health (Eastin, 2001). Health information-seeking behaviour varies depending on the age of adolescents.

Fast food refers to processed food prepared quickly in restaurants on-demand. Vogli, Kouvonen and Gimeno (2014) observe that changes that accompany the consumption of fast food are that it is easily in demand and is sold in restaurants and it can be taken out. The health implications of consumption of fast food vary; however, Reidpath, Burns, Mahoney and Townsend (2014) argue that fast food consumption has played a negligible role in the obesity epidemic.

\section{STATEMENT OF THE PROBLEM}

Available research suggests that fast food could constitute a health hazard because they are highly processed with very little nutritional value. The possible danger of (excessive) consumption of fast food notwithstanding, relatively little attention has been paid to this issue among scholars and health agencies especially as it relates to public knowledge of the food they consume.

In the contemporary world, health issues which usually get the attention of the World Health Organization (WHO), UN health organs and the various NGOs are often HIV/AIDS, Malaria, TB, Polio, Ebola and Yellow Fever among others. The literature on the consumption of fast food focuses more attention on its nutritional values than areas of wellness information concerning the public understanding of healthy eating, especially in the use of fast food. This situation necessitates people, especially the youth relying on the Internet for specific health information.

Studies have shown that the Internet is replete with wellness information that could inform healthy behaviour among young people. Although wellness information exists on the Internet, some youths hardly access such information but rely heavily on product information for the consumption of fast food. Regrettably, consumers of fast food that do not have access to the Internet wellness information may not be knowledgeable on health implications of fast food.

\section{OBJECTIVES OF THE STUDY}

This study investigated e-Health literacy and Internet wellness information on healthy eating of fast food among a. The specific objectives are:

1. To find out if adolescents of Awka South access Internet wellness information.

2. To investigate whether adolescents of Awka South access online information on healthy consumption of fast food.

3. To find out if adolescents of Awka South are knowledgeable on health implications of consumption of fast food. 


\section{RESEARCH QUESTIONS}

The following research questions guided the study:

1. To what extent are adolescents of Awka South exposed to Internet wellness information?

2. To what extent do adolescents of Awka South access online information on healthy consumption of fast food?

3. Are adolescent in Awka South knowledgeable of the health implications of consumption of fast food?

\section{REVIEW OF RELATED LITERATURE}

\section{Fast Food: An Overview}

Food is a substance that provides nourishment for people or animals and usually in solid form. Encyclopaedia Britannica (2015) defines food as a material consisting primarily of essential nutrients used in the body of an organism to gain energy. Encarta (2009) defines it as anything eaten to satisfy the appetite and to meet physiological needs for growth, to maintain all body processes, and to supply energy to maintain body temperature and activity. The definitions above differentiate food from other liquid forms of nutrition. It therefore implies that food is a solidified form of nourishment for people or animals.

The preparation of food determines its quality, and in the case of fast food, it is a processed food prepared quickly. It derives its fast tag from this quick and instantaneous mode of preparation. Fast food or junk food refers to the type of food prepared and served at terse notice making it a fast food. Most of the fast foodsare quite unhealthy (Arulogun and Owolabi, 2011). Most foods that are classified as fast food includes most junk food variances prepared in quick succession. Its main advantage is that fast food satiates a consumer's immediate hunger for nourishment. Like many businesses, fast food corporations cut costs to attract customers; thus, many of the main components of processed foods are cheap, while healthier fruits and vegetables are added to boost nutrients. Fast food represents food which is quickly prepared and eaten outside the home (Afolabi, Oyawoye, Sanni and Onabanjo, 2013). Examples of fast food include: Hamburgers, French fries, doughnuts, fried chicken and pizza etc.

\section{Health Implications of Consumption of Fast Food}

People eat fast food for different reasons. Although the primary reason for consumption of fast food is to satiate hunger, there are other health implications of fast food. Jayasinghe and De Silva (2014) argued that fast food may lead to an imbalance in their nutrient status and to increase the risk of diet-related non-communicable diseases.

One of the health challenges of consumption of fast food is obesity which is a chronic disease and defined as abnormal or excessive fat accumulation that presents a risk to human health. It is an increase in body weight that is linked with excessive calorie intake and lack of physical exercise. Mohiuddin (2020) opines that fast food/Junk food is tasty, comforting and convenient. Other health challenges associated with the consumption of fast food include: stroke, diabetes, heart diseases, headache/precipitation of migraine and neurodegeneration anc 
psychological changes. Shantosh, Fatin, Gan, Muhamad, Madhura, Javali and Patil (2019) observed that the harmful effect of fast food is associated with its preparation and constituents. Fast foods are rich in taste and aesthetic in appearance. Multiple food additives are added into them to enhance the taste, texture, freshness and eye-appeal to attract the consumer.

\section{Understanding E-Health Literacy and Internet Wellness}

E-Health literacy is a concept that helps an individual to access health information from electronic sources to solve health problems (Norman and Skinner, 2006). E-Health literacy has become an essential topic of research in recent years. On the other hand, Internet wellness covers the degree of use of the Internet. It measures the effectiveness of health information on the Internet, including the origin and message characteristics. Secondary sources of information comes from relevant material on e-health wellness

\section{Accessing Internet Information on Consumption of Fast Food}

Numerous studies such as Yan (2013) and (Percheski and Hargittai, 2011) have examined how students receive health information and concluded that Web has become a leading source for this group though a significant number of students make use of traditional mass media.

The Internet is composed of pages in need of quality editorial assessment (McLeod, 1998). To understand students' source preferences and use, Yan (2013) states that existing studies focused on examining criteria that cross-sectional consumer employ to evaluate health information on the Internet.

\section{THEORETICAL FRAMEWORK}

This study examined the Health Belief Model and Uses and Gratification approaches. Health Belief Model (HBM) has been extensively employed in social science research to explain health-related behaviour. Health Belief Model (HBM) is used to understand health behaviour and possible reasons for non-compliance with recommended health actions by providing guidelines for programme development. It allows planners to understand and address the reasons for non-compliance (Becker and Rosenstock, 1984). Usesand gratifications approach, on the other hand, explains the reasons people actively seek out specific media to satisfy particular needs. It explains mass communication in terms of what the audience benefit from mass media. It assumes that audience members are not passive consumers of media

\section{METHODOLOGY}

This study employed a survey with a population of 74,879 adolescents in Awka South LGA of Anambra State. The towns in Awka South LGA are: Awka, Amawbia, Nibo, Nise, Ezinato, Mbaukwu, Umuawulu, Okpuno and Isiagu. A sample of 400 respondents was drawn from the population using the Cochran (1977) formula for determining sample size. The instrument for data collection was the questionnaire. The frequency tables and percentages were used for data analysis.

\section{DATA ANALYSIS AND PRESENTATION}


A 30 - item questionnaire was used as data collection instrument for this study. The survey questions were in regard to the respondents' exposure to internet wellness information; access to online information on healthy consumption of fast food, and knowledge of the implication of consuming fast food. The total of 400 copies of questionnaire were distributed among the respondents in Awka South LGA of Anambra state. All the copies of the questionnaire were duly filled and returned, which indicates $100 \%$ return rate. The researcher distributed the questionnaire and collected them immediately. Few young people went home with it, but the researchers collected their phone numbers and called them within the week to receive the questionnaire.

Table One: Distribution of data according to the return rate of copies of the questionnaire.

\begin{tabular}{llll}
\hline S/N & Towns & Copies returned & Percentage (\%) \\
\hline 1. & Awka Town & 65 & 16.25 \\
2. & Amawbia Town & 43 & 10.75 \\
3. & NiboTown & 42 & 10.5 \\
4. & Nise Town & 40 & 10 \\
\hline 5 & Ezinator Town & 20 & $5 \%$ \\
6 & Mbaukwu Town & 43 & 10.75 \\
7 & Umuawulu Town & 42 & 10.5 \\
8 & Okpuno Town & 65 & 16.25 \\
9 & Isiagu Town & 40 & 10 \\
& & 400 & $\mathbf{1 0 0}$ \\
\hline
\end{tabular}

Table Two: Distribution of responses on regular exposure to Internet wellness information on fast food.

\begin{tabular}{lcc}
\hline Variable & Frequency & Percentage (\%) \\
\hline Strongly Agree & 159 & 39.8 \\
Agree & 155 & 38.8 \\
Undecided & 42 & 10.5 \\
Strongly Disagree & 33 & 8.3 \\
Disagree & 11 & 2.7 \\
\hline TOTAL & $\mathbf{4 0 0}$ & $\mathbf{1 0 0}$
\end{tabular}


Data in Table 2 above indicates that the respondents regularly expose themselves to Internet wellness information on fast food. Responses indicate that a little above 39\% (159) of the respondents strongly agreed while about $38 \%$ (155) of respondents agreed. There was also as low as $10.5 \%(42)$ who were undecided to the question on the regularity of exposure to Internet wellness information on fast food.

Table Three: Distribution on exposure to Internet wellness information on fast food in creating awareness of the positive benefits of fast food.

\begin{tabular}{lcc}
\hline Variable & Frequency & Percentage (\%) \\
\hline Strongly Agree & 151 & 37.8 \\
Agree & 149 & 37.3 \\
Undecided & 7 & 1.8 \\
Strongly Disagree & 70 & 17.5 \\
Disagree & 23 & 5.7 \\
\hline TOTAL & $\mathbf{4 0 0}$ & $\mathbf{1 0 0}$ \\
\hline
\end{tabular}

Data in Table Three above shows that a little above 37\% (151) strongly agreed while about $37 \%$ agreed that there are positive benefits of fast food. As low as a little above $1 \%$ were undecided.

Table Four: Distribution on access to online information on healthy consumption of fast food.

\begin{tabular}{lcc}
\hline Variable & Frequency & Percentage (\%) \\
\hline Yes & 364 & $91 \%$ \\
No & 36 & $9 \%$ \\
\hline TOTAL & $\mathbf{4 0 0}$ & $\mathbf{1 0 0 \%}$ \\
\hline
\end{tabular}

Data in Table Four above indicates that significant 91\%(364) of the respondents use the Internet for information on healthy consumption of fast food. The table equally shows that $9 \%$ (36) does not use Internet for information on healthy eating. The implication is that most youths in Awka South have access to the Internet information on fast food.

Table Five: Distribution of responses based on the significant rate of Internet access to wellness awareness on healthy eating.

\begin{tabular}{lcc}
\hline Variable & Frequency & Percentage (\%) \\
\hline Strongly agree & 346 & $86.4 \%$ \\
\hline
\end{tabular}


NNAMDI AZIKIWE UNIVERSITY Journal of Conmunication AND MEDIA Sudies Volume 1

Number 1 Volume 2

\begin{tabular}{lcc}
\hline Agree & 33 & $8.3 \%$ \\
Undecided & 0 & $0 \%$ \\
Strongly disagree & 15 & $3.8 \%$ \\
Disagree & 6 & $1.5 \%$ \\
\hline TOTAL & $\mathbf{4 0 0}$ & $\mathbf{1 0 0 \%}$ \\
\hline
\end{tabular}

Data in Table five above shows the degree of Internet access to wellness awareness of healthy eating. Those who strongly agreed indicated a significant rate of a little above $86 \%$ (346) respondents. This result implies that an increase in the influence of the Internet boosts the awareness of healthy eating.

Table Six: Distribution of responses on the use of Internet as a source of information for positive impacts on awareness of wellness of fast food.

\begin{tabular}{lcc}
\hline Variable & Frequency & Percentage (\%) \\
\hline Strongly Agree & 207 & 51.8 \\
Agree & 135 & 33.6 \\
Undecided & 6 & 1.5 \\
Strongly Disagree & 25 & 6.3 \\
Disagree & 27 & 6.8 \\
\hline TOTAL & $\mathbf{4 0 0}$ & $\mathbf{1 0 0}$ \\
\hline
\end{tabular}

Data in Table Six above shows that there is a significant positive impact of the use of the Internet in creating awareness of fast food. A little above $51 \%$ (207) of the respondents strongly agreed while about $33 \%$ (135) of the respondents agreed to the positive impact of the Internet medium.

Table Seven: Health implications of consumptions of fast food

\begin{tabular}{llllllll}
\hline S/N & Variables & SA & A & D & SD & U & Mean \\
\hline 1. & Eating fast food can kill the kidney faster & 151 & 149 & 70 & 23 & 7 & 4.04 \\
$\mathbf{2}$ & Fast food can be slow indigestion & 182 & 158 & 48 & 11 & 1 & 4.27 \\
3. & Fast food increases the rate of hypertension & 130 & 129 & 101 & 34 & 6 & 3.86
\end{tabular}


\begin{tabular}{llllllll}
\hline 4 & Fast food can block the intestine after a long & 194 & 116 & 49 & 21 & 20 & 4.11
\end{tabular} time

$\begin{array}{llllllll}\text { 5. } & \text { Eating fast food can lead to excess weight } & 188 & 184 & 12 & 13 & 3 & 4.48\end{array}$ gain

\begin{tabular}{llllllll}
\hline 6. & Eating fast food can be linked to cancer & 191 & 150 & 38 & 5 & 16 & 4.24
\end{tabular}

From the responses in Table seven above, there is a preponderance of affirmative answer by the respondents. Using mean scores of the items in Table seven, it indicates high significance on the following negative effects of the consumption of fast food due to lack of wellness information. There is a sign that lack of access to information on fast food due to the following: (a) it affects the kidney as shown by mixed solutions of $300(75.5 \%)$ respondents that strongly agreed and agreed respectively, (b) it slows digestion with mixed solutions of $340(85 \%)$, (c) fast food increases the rate of hypertension with mixed solutions of 259 $(64.8 \%),(d)$ it blocks the intestine after a long time with a combined strongly agree and agree responses of $310(77.5 \%)$, (e) excess fast food can lead to excess weight loss with combined strongly agree and agree answers of $372(93 \%)$, and (f) eating fast food can lead to cancer with combined strongly agree and agree answers of $341(85.5 \%)$.

\section{CONCLUSION}

Based on the findings in this study, the following conclusions were proffered:

a. Exposure to Internet wellness information is mostly dependent on the level of accessibility to Internet-enabled devices and the level of education of the user.

b. Frequency of exposure to Internet wellness information specifying fast food as unhealthy processed food can lead to increased knowledge of fast food as unhealthy processed food.

c. Increased exposure to harmful or unhealthy information about a given matter induces negative behaviour change toward such subject. Once there is negative information about a product via the Internet, the chances of continuous consumption of such product is low.

\section{REFERENCES}

Afolabi, W., Oyawoye, O., Sanni, S. and Onabanjo, O. (2013). Proximate and cholesterol composition of selected fast foods sold in Nigeria. Nigerian FoodJournal, 31: 70- 76.

Arulogun O. S. and Owolabi M. O. (2011). Fast food consumption pattern among undergraduates of the University of Ibadan, Nigeria: Implications for Nutrition Education' Journal of Agriculture and Food Technology, 1(6), 89-93.

Cassell, M. M., Jackson, C. and Cheuvront, B. (1998). Health Communication on the Internet: An effective channel for health behavior change? Journal of Health Communication, $3,71-82$.

Cochran, W. G. (1977). Sampling techniques (3rd Edition). New York: John Wiley. 
Eastin, M. S. (2001). Credibility Assessments of Online Health Information: The Effects of Source Expertise and Knowledge of Content. Journal of Computer-Mediated Communication 6 (2) 112-125.

Encarta (2009). Food. Redmond, WA: Microsoft Corporation, 2008.

Encyclopedia Britannica (2015). Food.. Encyclopcedia Britannica Ultimate Reference Suite. Chicago: Encyclopædia Britannica.

Internet World Stats (2012). Internet Usage Statistics for Africa, Available at http://www.internetworldstats.com/stats1.htm, Accessed September, 27, 2019.

Jayasinghe, J. and De Silva, L. (2014). Fast Food Consumption and Health Status of Students of a University in Sri Lanka, Journal of Food and Agriculture 2014, 7 (1 \& 2): 38 50

Kitikannakorn N. and Sitthiworanan C. (2009). Searching for health information on the Internet by undergraduate students in Phitsanulok, Thailand. International Journal of Adolescent Medicine and Health, 21, 313-318.

McLeod, S. D. (1998) The quality of medical information on the Internet: a new public health concern. Archives of Ophthamology, 116, 1663-1665.

Mohiuddin, A. (2020). Fast Food Addiction: A Major Public Health Issue. Archives in Biomedical Engineering \& Biotechnology, 15-21.

Norman, C.D. and Skinner, H. A (2006).e-Health Literacy: Essential Skills for Consumer Health in a Networked World"8 (2), $224-231$

Percheski, C. and Hargittai, E. (2011). Health information-seeking in the digital age. Journal of American College Health, 59, 5, 379-386.

Reidpath, D., Burns, R., Garrard, J., Mahoney, M. and Townsend, M. (2014). An ecological study of the relationship between social and environmental determinants of obesity. Health Place, 8:1-5.

Richards, B., Colman, A. W. and Hollingsworth, R. A. (1998). The current and future role of the Internet in patient education. International Journal of Medical Informatics, 50(1), 279-285.

Scott, S. D. and Gilmour, J. and Fielden, J. (2008). Nursing students and internet health information. Nurse Education Today, 28, 993-1001.

Shaikh I. A., Shaikh M. A., Kamal A. and Masood S. (2008). Internet access and utilization for health information among university students in Islamabad. Journal of Ayub Medical College, Abbottabad, 20, 153-156.

Shantosh, K., Fatin, A., Gan, A., Muhamad, N., Madhura, T., Javali, S. and Patil, P. (2019). Eat fast, die young: the pattern of fast food consumption amongst internationa 
medical students. Journal of Advances in Medicine and Medical Research, 31(3): 116.

Stellefson, M.; Hanik, B.; Chaney, B.; Chaney, D.; Tennant, B. and Chavarria, E. A.(2011).eHealth Literacy Among College Students: A Systematic Review With Implications for e-Health Education". 13 (4).

Vance, K., Howe, W. and Dellavalle, R. P. (2009). Social internet sites as a source of public health information. Dermatologic clinics, 27(2), 133-136.

Vogli, R., Kouvonen, A. and Gimeno, D. (2014). The influence of market deregulation on fast food consumption and body mass index: a cross-national time series analysis. Bull World Health Organ ;92:99-107.

Yan, Z. (2013). An exploratory study of users' preference and uses of sources for seeking health information. Fort Worth, TX: Iconference.

Yuri Quintana, Y., Feightner, J. W., Wathen, C.N., Sangster, L.M., and Marshall, J.N. (2001). Providing Quality Preventive Health Information on the Internet: Consumers' Perspectives. Can Fam Physician, 47, 1759-1765. 